\title{
Acta
Biochimica
Polonica
}

Vol. 50 No. $3 / 2003$

$595-601$

QUARTERLY

\section{Signal transducer and activator of transcription STAT3 plays a major role in gp130-mediated acute phase protein gene activa- $\operatorname{tion}^{\star \star}$}

\author{
Petra May ${ }^{\bowtie}$, Ute Schniertshauer, Claudia Gerhartz, Friedemann Horn and \\ Peter C. Heinrich
}

\begin{abstract}
Department of Biochemistry, Universitätsklinikum, Rheinisch-Westfälische Technische Hochschule Aachen, Aachen, Germany
\end{abstract}

Received: 30 May, 2003; revised: 29 August, 2003; accepted: 8 September, 2003

Key words: STAT transcription factors, gp130, acute phase proteins, immediate early genes

\begin{abstract}
Interleukin- 6 is a potent inducer of acute-phase response gene transcription. The intracellular signal transduction mechanisms by which this and other biological effects of the cytokine are achieved include activation of the JAK-STAT signaling pathway. More specifically, activation of the signal transducers and activators of transcription STAT1, 3, and 5 in response to IL-6 has been described.

We examined the relative potency of these three STAT factors for the activation of acute-phase gene promoters in HepG2 cells in a reporter gene-based assay, where specific STAT factors could be activated via recombinant receptor constructs bearing different STAT-recruiting modules. These experiments indicate that amongst the STAT factors known to be activated by IL-6 STAT3 is the most potent activator of acute-phase gene transcription.
\end{abstract}

Living organisms respond to tissue injury and infection with a highly complex reaction, also known as acute phase response (Gordon $\&$ Koj, 1985). The liver plays a pivotal role in the acute phase reaction: hepatocytes synthe- size and secrete acute phase proteins particularly after stimulation with interleukin-6.

Interleukin- 6 is a cytokine with diverse biological functions. Depending on the target tissue, it induces, for instance, the differentia-

\footnotetext{
${ }^{\star}$ Presented at the XXX Winter School of Faculty of Biotechnology, Jagiellonian University, Kościelisko, Poland, 28th February-4th March, 2003.

This work was supported by grants from the Deutsche Forschungsgemeinschaft (Bonn Bad Godesberg) and the Fonds der Chemischen Industrie (Frankfurt am Main).

${ }^{{ }}$To whom correspondence should be addressed: present address: Department of Molecular Genetics, UTSW Medical Center, 5323 Harry Hines Blvd., Dallas, TX 75390-9046, U.S.A.; phone: 001-214 648 3962; fax: 001-214 648 8804; e-mail: Petra.May@UTSouthwestern.edu

Abbreviations: CAT, chloramphenicol acetyltransferase; CRP, C-reactive protein; EPO, erythropoietin; IL-6, interleukin-6; JAK, Janus kinase; STAT, signal transducer and activator of transcription.
} 
tion of B-lymphocytes to antibody producing plasma cells, it leads to acute-phase protein production and secretion in hepatocytes, and can inhibit proliferation of melanoma cells (Akira et al., 1993; Heinrich et al., 1998). The network of intracellular signal transduction activated by IL- 6 has been studied intensely and the JAK-STAT pathway has been shown to be critical for IL-6 signaling. After binding to its low affinity $\alpha$-receptor (gp80), IL-6 induces homodimerization of the transmembrane signal transducer gp130, thereby activating the Janus kinases JAK1, JAK2 and Tyk2, which then phosphorylate gp130 on various tyrosine residues and in turn the transcription factors STAT1, STAT3 and STAT5. After their phosphorylation, the STATs homoand/or heterodimerize and translocate to the nucleus, where they regulate the transcription of their target genes (Heinrich et al., 1998; 2003).

The sets of JAKs and STATs that are activated by IL- 6 are also involved in the signal transduction of other cytokines and growth factors, which raises the question of how specificity of the biological response can be achieved in the JAK-STAT signaling pathway.

We addressed this question by examining what role the individual STAT factors known to be activated by IL- 6 play in the induction of a specific IL-6 dependent biological response. For this study we chose the activation of acute-phase and immediate-early gene promoters as a read-out, and we measured their STAT-mediated activation in reporter gene assays.

Using this experimental system, we found that of the IL- 6 activated STATs, STAT3 is the key mediator for the induction of acute-phase protein and immediate early gene promoters, i.e. STAT3 is the critical STAT component for the IL-6 induced acute-phase response of the liver. These results provide one possible mechanism by which specificity can be maintained in a seemingly highly redundant signal transduction network.

\section{MATERIALS AND METHODS}

D-Threo-[dichloroacetyl-1- $\left.{ }^{14} \mathrm{C}\right]$-chloramphenicol $(53 \mathrm{mCi} / \mathrm{mmol})$ was purchased from Amersham (Braunschweig, Germany). Recombinant human erythropoietin $\left(2.2 \times 10^{5}\right.$ $\mathrm{U} / \mathrm{mg}$ protein) was from Boehringer Ingelheim (Penzberg, Germany). Recombinant IL-6 was prepared according to the method described by Arcone et al. (1991) and had a specific activity of $1 \times 10^{6} \mathrm{BSF} 2 \mathrm{U} / \mathrm{mg}$ protein.

Plasmids. The construction of expression plasmids for the different receptor chimeras was described elsewhere (Gerhartz et al., 1996). For expression in HepG2 cells, the constructs were subcloned from the pSVL vector (Pharmacia, Freiburg, Germany) to Rc/CMV (Invitrogen, Leek, The Netherlands). The expression plasmids for the STAT factors were kindly provided by C. Schindler (New York, U.S.A.) (pSVL-STAT1), J.E. Darnell (New York, U.S.A.) (pSVL-STAT3), and W. Doppler (Innsbruck, Austria) (pECESTAT5A). STAT-1- and STAT-3-cDNAs were also subcloned into Rc/CMV. pCR3LacZ was from Invitrogen (Leek, The Netherlands). pEMBL8-CAT-CRP219, pEMBL8-CAT-Hp186, pEMBL8-CAT-Hpx 175, and pEMBL8-CATHpx2000 were kindly provided by V. Poli (Rome, Italy). pBLCAT2- $\gamma$ fib935 and pBLCAT2-JunB were described in (Lüttiken et al., 1995).

Cell culture procedures and transfection of HepG2 cells. HepG2 cells were grown in DMEM/F12 (Gibco, Eggenstein, Germany) supplemented with $10 \%$ FCS (fetal calf serum) and $100 \mathrm{U} / \mathrm{ml}$ penicillin and $100 \mu \mathrm{g} / \mathrm{ml}$ streptomycin (Gibco, Eggenstein, Germany) at $37^{\circ} \mathrm{C}$ in a $5 \% \mathrm{CO}_{2}$ atmosphere.

HepG2 cells were transfected by calcium-phosphate precipitation. Briefly, cells were washed twice with PBS (phosphate-buffered saline) half an hour before transfection and their culture medium was changed to DMEM. For transfection, $62 \mu \mathrm{l} 2 \mathrm{M} \mathrm{CaCl}_{2}$ was added to 20 $\mu \mathrm{g}$ DNA/ $100 \mathrm{~mm}$ dish. The solution was then 
mixed with $500 \mu \mathrm{l} 2 \times$ HBS (10 g/l Hepes, 16 $\mathrm{g} / \mathrm{l} \mathrm{NaCl}, 0.74 \mathrm{~g} / \mathrm{l} \mathrm{KCl}, 0.25 \mathrm{~g} / 1 \mathrm{NaH}_{2} \mathrm{PO}_{4}$. $\mathrm{H}_{2} \mathrm{O}, 2 \mathrm{~g} / \mathrm{l}$ glucose, $\mathrm{pH}$ 7.05) and added to 10 $\mathrm{ml}$ DMEM. The transfection mixture remained on the cells for 5-15 h.

Reporter gene assays. Twenty four hours after transfection, HepG2 cells were stimulated with erythropoietin $7 \mathrm{U} / \mathrm{ml}$ or IL-6 100 $\mathrm{U} / \mathrm{ml}$ for $20 \mathrm{~h}$. Then they were washed twice with PBS and incubated in $1 \mathrm{ml}$ harvesting buffer $(0.15 \mathrm{M} \mathrm{NaCl}, 1 \mathrm{mM}$ EDTA, $40 \mathrm{mM}$ Tris/HCl, pH 7.4) per $100 \mathrm{~mm}$ dish for $5 \mathrm{~min}$ at RT. After scraping and centrifugation the cells were resuspended in $200 \mu \mathrm{l} 0.25 \mathrm{M}$ Tris/ $\mathrm{HCl}, \mathrm{pH} 7.8$, and were then subjected to three freeze-thaw cycles in liquid nitrogen. Finally, the lysates were centrifuged and the protein concentration of the supernatants was determined by the Bradford method.

For CAT-assays cell lysates containing $5 \mu \mathrm{g}$ protein were diluted to a volume of $84 \mu \mathrm{l}$ with $0.25 \mathrm{M}$ Tris $/ \mathrm{HCl}, \mathrm{pH} 7.8$, and incubated at $60^{\circ} \mathrm{C}$ for $10 \mathrm{~min}$. Subsequently, $12 \mu \mathrm{l}$ butyryl-CoA ( $2 \mathrm{mg} / \mathrm{ml}$, Sigma, Deisenhofen, Germany) and $4 \mu \mathrm{l}$ D-threo-[dichloroacetyl-1- $\left.{ }^{14} \mathrm{C}\right]-$ chloramphenicol were added and the mixture was incubated at $37^{\circ} \mathrm{C}$ for $1 \mathrm{~h}$. Butyrylated chloramphenicol and the unmodified compound were separated by organic extraction with 200 $\mu$ l xylol. After three washing steps with TE (10 $\mathrm{mM}$ Tris/HCl, $\mathrm{pH} 7.4,1 \mathrm{mM}$ EDTA) the organic phase was added to $1 \mathrm{ml}$ rotiszint 2200 (Roth, Karlsruhe, Germany) and its radioactivity was determined in a scintillation counter. The result was considered the crude CAT activity, which was corrected for the transfection efficiency of the respective experiment by division through the activity of the enzyme $\beta$-galactosidase, an expression plasmid for which was always cotransfected ( $3 \mu \mathrm{g}$ pCR3LacZ per $100 \mathrm{~mm}$ dish).

For $\beta$-Gal-assays cell lysates containing 100 $\mu \mathrm{g}$ protein were mixed with $500 \mu \mathrm{l} \beta$-Gal buffer $\left(60 \mathrm{mM} \mathrm{Na}_{2} \mathrm{HPO}_{4}, 40 \mathrm{mM} \mathrm{NaH} \mathrm{PO}_{4}, 1\right.$ $\mathrm{mM} \mathrm{KCl}, 1 \mathrm{mM} \mathrm{MgCl} 2,38.6 \mu \mathrm{l} \beta$-mercaptoethanol per $100 \mathrm{ml}$ solution) and warmed to $37^{\circ} \mathrm{C}$. $o$-Nitrophenyl- $\beta$-D-galactopyranoside (100 $\mu \mathrm{l}, 1$ $\mathrm{mg} / \mathrm{ml}$ in $\mathrm{H}_{2} \mathrm{O}$ ) was added and the mixture was incubated at $37^{\circ} \mathrm{C}$. When a yellow color change of the samples was observed, the reaction was stopped by the addition of $250 \mu \mathrm{l} 1 \mathrm{M} \mathrm{Na}_{2} \mathrm{CO}_{3}$, $\mathrm{pH}$ 8. The incubation time was recorded and the $\mathrm{A}_{420}$ of the probes was determined. $\beta$-Gal activity was calculated as activity $(\mathrm{U} / \mu \mathrm{g})=$ $\left(\mathrm{A}_{420} \times 6000\right) /$ (incubation time in minutes $\times$ amount of protein in $\mu \mathrm{g}$ ).

\section{RESULTS AND DISCUSSION}

To examine the relative importance of the IL6-activated STAT factors STAT1, STAT3 and STAT5 for the cytokine's biological effects, we determined by reporter gene assays their ability to activate the promoters of several IL6-responsive genes in HepG2 cells. Promoters of different acute phase proteins ( $\gamma$-fibrinogen, CRP, haptoglobin, and hemopexin) and immediate early (junB) genes, which all contain STAT binding sites (Fujitani et al., 1994; Zhang et al., 1995; Zhang et al., 1996; Oliviero \& Cortese, 1989; Kim \& Baumann, 1997; Immenschuh et al., 1994; 1995), were cloned in front of the bacterial chloramphenicol acetyltransferase gene and HepG2 cells were transfected with these constructs. After stimulation with IL-6, CAT-activity was induced from 5 -fold (hemopexin promoter) to over 20 -fold ( $\gamma$-fibrinogen promoter) in the transfected cells (Fig. 1).

As mentioned above, IL-6 has been reported to activate three different STAT factors, as well as signaling networks different from the JAK/STAT pathway (for a review see Heinrich et al., 2003). In order to be able to study separetely the effects of activated STAT1, STAT3 or STAT5, we made use of synthetic receptor constructs, which specifically recruit and activate a single type of STAT. These recombinant receptors consist of the extracellular domain of the erythropoietin receptor and the transmembrane and membrane proximal intracellular (box1/2) domains of gp130. To the C-terminus of these chimeras, oligo- 


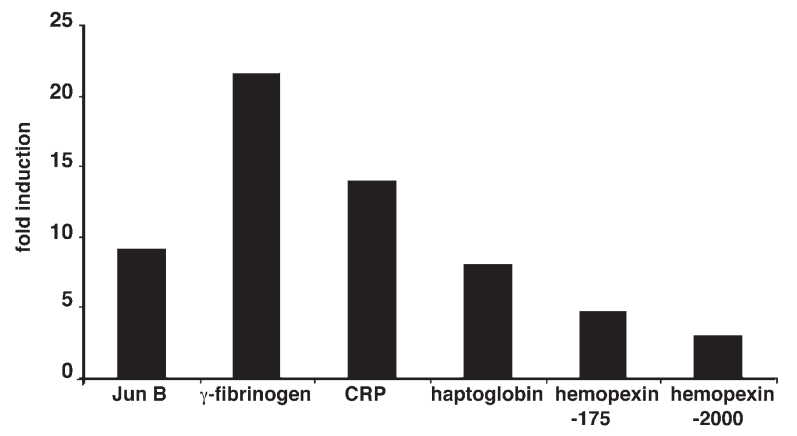

Figure 1. Activation of reporter constructs by stimulation of transfected HepG2 cells with IL-6.

HepG2 cells were transfected with $12 \mu \mathrm{g}$ reporter gene plasmid DNA and $3 \mu \mathrm{g}$ pCR3LacZ per $100 \mathrm{~mm}$ dish. After stimulation with $100 \mathrm{U}$ IL-6/ml for $20 \mathrm{~h}$ the cells were lysed and examined for CAT and $\beta$-galactosidase activities, where $\beta$-galactosidase activity served as internal control for transfection efficiency. The diagram shows the induction of reporter gene activity in stimulated versus unstimulated cells.

nucleotides coding for consensus binding sites for the different STAT factors were fused (Fig. 2). As shown by gel shift experiments in earlier studies, stimulation with erythropoietin leads to the activation of the recombinant receptors independently of endogenous gp130 and allows specific recruitment and phosphorylation of the respective STAT factors (Gerhartz et al., 1996; May et al., 1996).

To compare the effects of activated STAT1, STAT3 and STAT5 on the acute phase protein and immediate early gene promoters introduced above, we cotransfected HepG2 cells with the different receptor chimeras and the reporter gene constructs. After $20 \mathrm{~h}$ of stimulation with erythropoietin, cell lysates were prepared and analyzed for CAT activity. As shown in Fig. 3A, the promoters of the acute-phase proteins $\gamma$-fibrinogen, CRP, and haptoglobin, and to a lesser degree that of hemopexin, were induced predominantly by stimulation of the STAT3-activating chimera Eg-Y767. Nevertheless, the $\gamma$-fibrinogen and haptoglobin promoters, as well as the larger hemopexin promoter fragment, were also inducible by activation of Eg-YLVLD (recruiting
STAT5), and to a limited extent all the acute-phase promoters examined responded to the stimulation of Eg-Y440 (recruiting STAT1), too. Lastly, the promoter of the im-

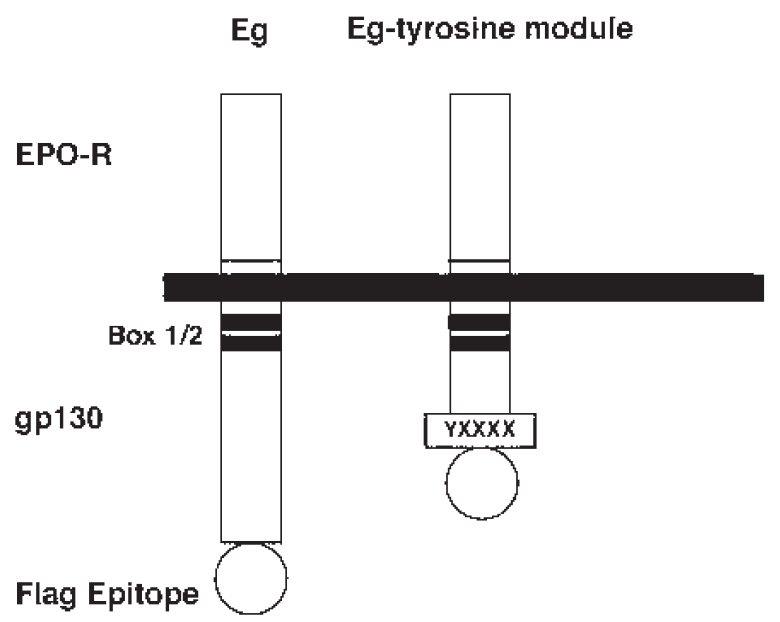

Figure 2. Schematic representation of erythropoietin receptor/gp130 chimeras.

The full-length chimera Eg consists of the extracellular part of the erythropoietin receptor and the transmembrane and intracellular domains of gp130. To obtain receptors that specifically activate individual STAT factors, the intracellular part of gp130 was truncated after box $1 / 2$ and a recruiting motif for the respective STAT factor was added at this position (Eg-tyrosine module). Finally, the recombinant receptor constructs contain FLAG epitopes at their C-termini. A FLAG antibody was used to verify the surface expression of the different receptor chimeras (not shown).

mediate-early gene junB reacted to the stimulation of Eg-Y440 and Eg-Y767 only.

To investigate further the apparent dominance of STAT3 in the activation of the IL-6-responsive promoters, we cotransfected plasmids coding for the different STAT factors together with the corresponding receptor chimeras and the reporter gene constructs.

As shown in Fig. 3B, in cells cotransfected with the chimera Eg-Y767 and with STAT3 stimulation of the STAT3 recruiting receptor led to robust induction of reporter gene transcription from all promoter constructs. Specific activation of cotransfected STAT1 and STAT5, on the other hand, augmented CAT activity only slightly. Just for the $\gamma$-fibrinogen 
A
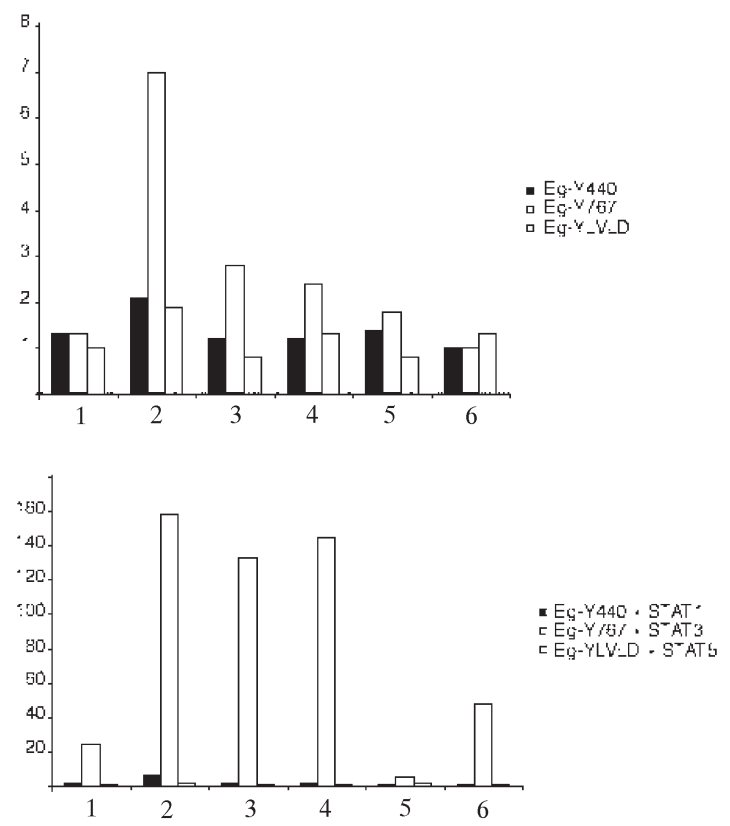

Figure 3. A. Stimulation of IL-6 responsive promoters by selective activation of STATs.

HepG 2 cells were transfected with $12 \mu \mathrm{g}$ reporter gene plasmid DNA, $4 \mu \mathrm{g}$ pCR3LacZ, and $4 \mu \mathrm{g}$ receptor construct plasmid. After stimulation with erythropoietin ( $7 \mathrm{U} / \mathrm{ml}$ ) for $20 \mathrm{~h}$, the cells were lysed and examined for reporter gene activity as described before. The diagram shows the induction of reporter gene activity in stimulated versus unstimulated cells. 1, JunB; 2, $\gamma$-fibrinogen; 3, CRP; 4, haptoglobin; 5, hemopexin, -175; 6, hemopexin, -2000 .

B. Overexpression of STAT factors unmasks the predominant effect of STAT3.

The experiment was carried out as described for A, but in addition to the receptor chimeras $4 \mu \mathrm{g}$ of the respective Rc/CMV STAT expression plasmids was cotransfected. 1, JunB; 2, $\gamma$-fibrinogen; 3, CRP; 4, haptoglobin; 5 , hemopexin, $-175 ; 6$, hemopexin, -2000 . promoter construct cotransfection of STAT1 increased responsivity to activation of Eg-Y440 significantly, but still the reporter gene transcription in response to STAT1 was modest compared to that in response to STAT3.

To exclude secondary effects of STAT3 overexpression and activation after prolonged stimulation, we repeated the experiment described above, but this time stimulation with erythropoietin was carried out for $4 \mathrm{~h}$ only. As is illustrated in Table 1, also under these experimental conditions STAT3 was a much more potent activator of reporter gene transcription than either of the other two factors, only the absolute values of induction were lower than those achieved after longer stimulation of the transfected cells.

Taken together, these results indicate that STAT3 plays a pivotal role in the intracellular mediation of IL-6-induced gene transcription, which holds true for both type I and type II acute phase proteins as well as for the immediate early gene junB.

In more general terms this means that, although cytokines might activate several and overlapping sets of STATs, specificity of their action can still be achieved by restricting a given biological response, e.g. the transcription of acute-phase protein genes, to a specific activated STAT factor.

The mechanism by which this restriction is achieved may include tissue-specific expression of STAT factors. In addition, interaction of STAT proteins with transcriptional co-activators could define their ability to acti-

Table 1. STAT-dependent activation of IL-6-responsive promoters after a short period of stimulation.

This experiment was carried out as described for Fig. 3 B, solely the time of stimulation with erythropoietin was reduced to $4 \mathrm{~h}$.

\begin{tabular}{l|lll} 
& Eg-Y440, STAT1 & Eg-Y767, STAT3 & Eg-YLVLD, STAT5 \\
\hline Jun B & 0.8 & 2.2 & 0.9 \\
$\gamma$-Fibrinogen & 0.6 & 19.0 & 0.9 \\
CRP & 1.6 & 90.6 & 0.8 \\
Haptoglobin & 1.2 & 15.5 & 1.0 \\
Hemopexin, -175 & 1.5 & 2.5 & 1.1 \\
Hemopexin, -2000 & 1.1 & 5.3 & 2.5
\end{tabular}


vate a given promoter. Several STATs have been shown to regulate gene expression in concert with other DNA-binding molecules and for STAT3, for example, functional interactions with NcoA/SRC1a (Giraud et al., 2002) and c-jun (Zhang et al., 1999) have been shown, amongst others. It is likely that similar interactions make activated STAT3 such a potent inducer of acute phase protein gene expression, a biological role that has been confirmed in an animal model of genetically modified mice that lack hepatic STAT3 and are unable to upregulate acute phase protein gene expression after the induction of acute phase response (Alonzi et al., 2001).

The authors like to thank Valeria Poli (Torino) for the generous gift of the acute phase promoter constructs.

\section{R E F E R E N C E S}

Akira S, Taga T, Kishimoto T. (1993) Interleukin- 6 in biology and medicine. $A d v$ Immunol.; 54: 1-78.

Alonzi T, Maritano D, Gorgoni B, Rizzuto G, Libert C, Poli V. (2001) Essential role of STAT3 in the control of the acute-phase response as revealed by inducible gene inactivation [correction of activation] in the liver. Mol Cell Biol.; 21: 1621-32.

Arcone R, Pucci P, Zappacosta F, Fontaine V, Malorni A, Marino G, Ciliberto G. (1991) Single-step purification and structural characterization of human interleukin-6 produced in Escherichia coli from a T7 RNA polymerase expression vector. Eur $J$ Biochem.; 198: 541-7.

Fujitani Y, Nakajima K, Kojima H, Nakae K, Takeda T, Hirano T. (1994) Transcriptional activation of the IL-6 response element in the junB promoter is mediated by multiple Stat family proteins. Biochem Biophys Res Commun.; 202: 1181-7.

Gerhartz C, Heesel B, Sasse J, Hemmann U, Landgraf C, Schneider-Mergener J, Horn F, Heinrich PC, Graeve L. (1996) Differential activation of acute phase response factor/STAT3 and STAT1 via the cytoplasmic domain of the interleukin 6 signal transducer gp130. I. Definition of a novel phosphotyrosine motif mediating STAT1 activation. J Biol Chem.; 271: 12991-8.

Giraud S, Bienvenu F, Avril S, Gascan H, Heery DM, Coqueret O. (2002) Functional interaction of STAT3 transcription factor with the coactivator NcoA/SRC1a. J Biol Chem.; 277: 8004-11.

Gordon AH, Koj A. (1985) The acute phase response to injury and infection. Elsevier, Amsterdam.

Heinrich PC, Behrmann I, Muller-Newen G, Schaper F, Graeve L. (1998) Interleukin-6-type cytokine signalling through the gp130/Jak/STAT pathway. Biochem J.; 334: 297-314.

Heinrich PC, Behrmann I, Haan S, Hermanns HM, Müller-Newen G, Schaper F. (2003); Principles of IL-6-type cytokine signalling and its regulation. Biochem J.; 374: 1-20.

Immenschuh S, Nagae Y, Satoh H, Baumann H, Muller-Eberhard U. (1994) The rat and human hemopexin genes contain an identical interleukin-6 response element that is not a target of CAAT enhancer-binding protein isoforms. J Biol Chem.; 269: 12654-61.

Immenschuh S, Song DX, Satoh H, Muller-Eberhard U. (1995) The type II hemopexin interleukin-6 response element predominates the transcriptional regulation of the hemopexin acute phase responsiveness. Biochem Biophys Res Commun.; 207: 202-8.

Kim H, Baumann H. (1997) The carboxyl-terminal region of STAT3 controls gene induction by the mouse haptoglobin promoter. J Biol Chem.; 272: 14571-9.

May P, Gerhartz C, Heesel B, Welte T, Doppler W, Graeve L, Horn F, Heinrich PC. (1996) Comparative study on the phosphotyrosine motifs of different cytokine receptors involved in STAT5 activation. FEBS Lett.; 394: 221-6. 
Oliviero S, Cortese R. (1989) The human haptoglobin gene promoter: interleukin-6-responsive elements interact with a DNA-binding protein induced by interleukin-6. EMBO J.; 8: 1145-51.

Zhang Z, Fuentes NL, Fuller GM. (1995) Characterization of the IL- 6 responsive elements in the gamma fibrinogen gene promoter. $J$ Biol Chem.; 270: 24287-91.
Zhang D, Sun M, Samols D, Kushner I. (1996) STAT3 participates in transcriptional activation of the C-reactive protein gene by interleukin-6. J Biol Chem.; 271: 9503-9.

Zhang X, Wrzeszczynska MH, Horvath CM, Darnell JE Jr. (1999) Interacting regions in Stat3 and c-Jun that participate in cooperative transcriptional activation. Mol Cell Biol.; 19: $7138-46$. 